American Journal of Biochemistry and Biotechnology 3 (3): 118-124, 2007

ISSN 1553-3468

(C) 2007 Science Publications

\title{
Development of Cell-Responsive Nanophase Hydroxyapatite for Tissue Engineering
}

\author{
${ }^{1}$ R. Murugan and ${ }^{2} \mathrm{~S}$. Ramakrishna \\ ${ }^{1}$ NanoScience Technology Center, University of Central Florida, Orlando, FL 32826, USA \\ ${ }^{2}$ Nanoscience and Nanotechnology Initiative, Division of Bioengineering, National University of \\ Singapore, Singapore 117576
}

\begin{abstract}
Scaffold plays a critical role in engineering bone tissues by providing necessary structural support for the cells to accommodate and guiding their growth in the three dimensional (3D) space. Therefore, designing scaffold that mimic composition and structural aspects of the bone is of great importance to promote cell adhesion, cell-matrix interactions, osteointegration, tissue formation and continued function. Nanophase hydroxyapatite (HA) is a class of bioceramic material that mimics the bone mineral in composition and structure and possesses unique capabilities for surface interactions with biological entities than conventional HA; therefore, it can be used as a scaffolding system in engineering bone tissues. This article reports synthesis, characterization, and evaluation of nanophase HA for use in bone tissue engineering and how the nanophase characteristics help the HA to promote cells/tissue growth with suitable experimental examples.
\end{abstract}

Key words: Nanomaterials, hydroxyapatite, scaffold, cell-matrix interactions, bone tissue engineering

\section{INTRODUCTION}

Bone is a specialized form of connective tissue that provides a framework for the body, supporting it and giving it shape. Although bone is considered as the strongest tissue in the body, it often undergoes damage or defect, resulting from traumatic or non-traumatic destruction. Nowadays, bone defect is a common clinical problem for millions of people around the world, which has been conventionally treated with the help of bone tissues procured from the healthy donor site. The procured tissues are generally used in hip replacement, knee reconstruction, and spinal fusion surgeries. Depending on the location of reimplantation of the procured tissues, they are termed as autograft, allograft, or xenograft. Among them, autograft is considered as a gold standard and has been used for a long time with good clinical results, but its supply is limited and it does carry the risk of donor site morbidity. On the other hand, allograft and xenograft carry the possibility of pathogen transfer and graft rejection. To overcome these limitations, several biomaterials have been developed and clinically used in bone applications for more than half a century with many success and failure rates. There are several reasons for the failure of biomaterials, but one of the most important issues is lack of sufficient host tissue interaction and subsequent tissue generation around the biomaterials immediately after implantation, which occurs mainly due to the poor surface interaction of biomaterials with the host cells/tissue. Facilitation of favorable host tissue interaction and subsequent bone tissue formation essentially requires biomaterials with superior surface properties. In this concern, one may consider the use of nanophase biomaterials in place of conventional ones. However, bone tissue formation is comprised of a complex sequence of events that begins with cellular level; thereby a unique approach is to develop cell-responsive nanophase biomaterials through tissue engineering approach. As the mainstay of bone tissue engineering is the scaffolding system, it is always desirable if the scaffolding material mimics the natural bone in chemical composition and phase structure, apart from the surface and mechanical properties, to facilitate better osteointegration and subsequent bone tissue formation. In this regard, nanophase HA, $\mathrm{Ca}_{10}\left(\mathrm{PO}_{4}\right)_{6}(\mathrm{OH})_{2}$, may be considered a good choice of scaffolding material because it has close chemical and structural similarity to bone mineral and possess high surface area and superior mechanics than conventional

Corresponding Author: R. Murugan, NanoScience Technology Center, University of Central Florida, Orlando, FL 32826, USA. Tel: +1-407-882-1578; Fax: +1-407-882-2819 
HA. Keeping these astonishing merits in mind, the present article reports synthesis, characterization, and evaluation of nanophase HA for use in bone tissue engineering and how the nanocharacteristics help the HA to promote cells/tissue growth with suitable experimental examples.

\section{SYNTHESIS OF NANOPHASE HA}

HA is a class of bioceramic material frequently used in bone grafting ${ }^{[2-4]}$ and in bone drug delivery ${ }^{[5-7]}$. It is one of the most widely used biomaterials for various bone applications because it possesses most of the qualities required for bone tissue formation. There are a number of methods for processing HA either from natural sources (coral exo-skeleton and animal bone, for example) or from synthetic sources (inorganic chemical synthesis, for example ${ }^{[8-12]}$, but these studies focused on conventional microphase HA. Recently, nanophase HA has received much attention owing to its superior surface functional properties over its microphase counterpart, particularly surface area and surface roughness, which are the most imperative properties required to promote cell adhesion and cell-matrix interactions immediately after implantation. It is worth mentioning that the nanophase HA is one of the basic building blocks of natural bone that occupies about 60 wt.\%. It has also been proved that the nano HA, compared to conventional HA, promotes osteoblast adhesion, differentiation and proliferation, which leads to enhanced formation of new bone tissue within a short period $^{[13]}$. The nanophase HA is therefore perceived to be beneficial in bone tissue engineering as a new generation scaffolding system. There are several methods for the synthesis of nanophase HA, which include wet chemical ${ }^{[14,15]}$, solid state $^{[16]}$, hydrothermal $^{[17,18]}$, mechanochemical ${ }^{[19]}$, $\mathrm{pH}$ shock wave $^{[20]}$, and microwave processing ${ }^{[21]}$.

\section{Wet chemical method}

Wet chemical is one of the promising methods, widely used in synthesizing nano $\mathrm{HA}$ at low temperature. The HA powders synthesized by using this method are in homogeneous phase composition, but are poorly crystallized owing to the low temperature process. One common wet chemical method of synthesizing HA is based on the following equation, which uses calcium hydroxide and orthophosphoric acid as calcium and phosphorous precursors, respectively.

$10 \mathrm{Ca}(\mathrm{OH})_{2}+6 \mathrm{H}_{3} \mathrm{PO}_{4} \rightarrow \mathrm{Ca}_{10}\left(\mathrm{PO}_{4}\right)_{6}(\mathrm{OH})_{2}+13 \mathrm{H}_{2} \mathrm{O}$

Recently, rod-like nano HA was synthesized by using this method ${ }^{[14]}$. In brief, $\mathrm{H}_{3} \mathrm{PO}_{4}$ solution $(0.3 \mathrm{M})$ was added drop-wise to $0.5 \mathrm{M} \mathrm{Ca}(\mathrm{OH})_{2}$ solution under continuous stirring at room temperature, while the $\mathrm{pH}$ was kept above 10.5 by the addition of ammonia solution. Stirring was maintained for further $16 \mathrm{~h}$ after complete addition of the reactants. The precipitate thus obtained was further aged for a week and was examined for their phase purity and chemical composition using various analytical methods. The results indicated the possibility of producing phase pure, nanosize, and rodlike HA by using wet chemical method. Our group, Murugan et al. ${ }^{[15]}$ also synthesized HA nanoparticles by using this method, and extensively studied their physicochemical and physiological properties at body $\mathrm{pH}$, which are discussed in section 6 in detail for the interest of readers. The results clearly showed the enhanced resorbable characteristics of nano HA than their microscale counterpart, owing to their larger surface area to volume ratio, which ultimately makes the nano HA highly surface reactive. Based on these experimental data, wet chemical method is one of the most promising methods for the synthesis of nano HA.

\section{Solid state reaction}

Solid state reaction has generally been used for the processing of HA at high temperature. The HA powders synthesized by this method usually have irregular shapes with larger grain size, and they quite often exhibit heterogeneity in the phase composition, owing to chemical reactions resulting from small diffusion coefficients of ions within the solid. A general formation of HA using solid state method is based on the following equation:

$4 \mathrm{CaCO}_{3}+\mathrm{CaHPO}_{4} \cdot 2 \mathrm{H}_{2} \mathrm{O} \rightarrow \mathrm{Ca}_{10}\left(\mathrm{PO}_{4}\right)_{6}(\mathrm{OH})_{2}+4 \mathrm{CO}_{2}$ $+14 \mathrm{H}_{2} \mathrm{O}$ at $1000-1300^{\circ} \mathrm{C}$

The key ingredients of this reaction are basically in solid phase in which $\mathrm{CaCO}_{3}$ act as a calcium precursor and $\mathrm{CaHPO}_{4} \cdot 2 \mathrm{H}_{2} \mathrm{O}$ act as a phosphorous precursor in the formation of HA. The solid state reaction typically takes place at a very high temperature $\left(\sim 1000^{\circ} \mathrm{C}\right)$. A method for the preparation of HA fibers was introduced using a solid phase reaction ${ }^{[16]}$. With this method, the HA fibers were produced by heating a compact consisting of calcium metaphosphate fibers with 
calcium hydroxide particles at $1000^{\circ} \mathrm{C}$ in air, and treated subsequently with dilute aqueous $\mathrm{HCl}$ solution to remove unwanted secondary phase substitution such as $\mathrm{CaO}$. The obtained fibers were characterized by various analytical methods, and the results confirmed the formation of HA with nanostructural features. Therefore, the solid state reaction can be considered as one of the methods for the synthesis of nano HA.

\section{Hydrothermal process}

Hydrothermal process involves the reaction of aqueous solution of calcium and phosphorous precursors at ambient temperature and pressure for the production of nano HA. This method enables the synthesis of crystallized HA with homogenous phase composition. The HA prepared by this method is easily sinterable, owing to the effects of high temperature and high pressure aqueous solutions. Zhang and Consalves ${ }^{[17]}$ synthesized nano HA by precipitating the precursors under hydrothermal conditions, and they studied its thermal stability in detail. By using this approach, they obtained rod-like, nano-sized HA with an average crystal size of 10 to $24 \mathrm{~nm}$, with respect to composition of precursors. They prepared a variety of HA powders with their $\mathrm{Ca} / \mathrm{P}$ ratio ranging from 1.66 to 1.73. In another interesting study ${ }^{[18]}$, the efficacy of nano HA as filler in fabricating tissue scaffold has been reported. The authors synthesized nano HA by a hydrothermal method. In brief, $2 \mathrm{~g}$ of ammonium phosphate dissolved in $37.5 \mathrm{~mL}$ of de-ionized water was added to $5.9 \mathrm{~g}$ of calcium nitrate dissolved in 22.5 $\mathrm{mL}$ of de-ionized water under stirring, and the $\mathrm{pH}$ of solution was adjusted to 12 by adding ammonia. The solution was then autoclaved under hydrothermal conditions (temperature at $170{ }^{\circ} \mathrm{C}$ and pressure at 19.5 $\mathrm{MPa}$ ) and subsequently aged for $5 \mathrm{~h}$. The precipitates thus obtained were cooled to room temperature, repeatedly washed with distilled water to remove the traces of ammonia and ammonium nitrate, dried at 80 ${ }^{\circ} \mathrm{C}$ overnight, and then ground to a fine powder. The characterization of powders indicated the formation and purity of HA. The HA particles were found to be ellipsoidal-shaped with needle-like morphologies. The particles had an average size of approximately $25 \mathrm{~nm}$ in width and $150 \mathrm{~nm}$ in length with aspect ratios ranging from 6 to 8 , indicating nanostructure features.

\section{Mechanochemical route}

Synthesis of nanophase HA by using mechanochemical route has gained interest in the recent years, owing to its simplicity. The processing conditions involved in this method slightly differ from the conventional wet chemical method. It is worth mentioning that the purity of material synthesized by conventional wet chemical method depends on the reaction $\mathrm{pH}$, whereas reaction through the mechanochemical route need not be under precise $\mathrm{pH}$ control. Nakamura et al. ${ }^{[19]}$ reported the synthesis of nano HA by using this method. The HA was prepared directly by milling a mixture comprising $\mathrm{Ca}(\mathrm{OH})_{2}$, $\mathrm{H}_{3} \mathrm{PO}_{4}$ and a dispersant, ammonium salt of polyacrylic acid. The reaction was carried out at room temperature. The prepared HA powders had relatively crystallized particles in nanometer regime. The average crystallite size was $20 \mathrm{~nm}$. The authors suggested some of the merits of this method, which includes (i) assisting deprotonation from brushite to form HA, and (ii) keeping high dispersibility and low viscosity of reaction sol. This method is of particular interest in synthesizing nano HA with ultra-fine crystallite sizes.

\section{pH shock wave method}

Another interesting method for the synthesis of nano HA is $\mathrm{pH}$ shock wave. Koumoulidis et al. ${ }^{[20]}$ reported the synthesis of HA in the form of lath-like monocrystalline particles using the precursors of $\mathrm{Ca}\left(\mathrm{H}_{2} \mathrm{PO}_{4}\right)_{2} \cdot \mathrm{H}_{2} \mathrm{O}$ and $\mathrm{CaCl}_{2}$. They employed a highenergy dispersing equipment to synthesize nano HA. The prepared HA was characterized by various analytical methods to determine their phase composition, structure, and texture. The results showed that the material has different $\mathrm{Ca} / \mathrm{P}$ molar ratio (1.43 to $1.66)$ with respect to processing conditions. The crystal grain sizes of HA was in the range of 140 to $1300 \mathrm{~nm}$ in length, 20 to $100 \mathrm{~nm}$ in width, and 10 to $40 \mathrm{~nm}$ in thickness. With reference to experimental results, this method seems to be quite interesting because it creates appropriate hydrodynamic conditions for lath-like particle growth in the [001] direction, which could not be obtained by using conventional mechanical stirring equipment.

\section{Microwave processing}

Microwave-assisted synthesis of nanophase ceramic materials is relatively a new class of method, 
which has recently gained interest in synthesizing nano HA. Sarig and Kahana ${ }^{[21]}$ reported the processing conditions for the rapid formation of nanocrystalline HA. The recipe for the synthesis of nano HA is briefly given as follows: the HA powder was precipitated from $\mathrm{CaCl}_{2} 10 \mathrm{mM}$ aqueous solution (A) and $\mathrm{NaH}_{2} \mathrm{PO}_{4} 6$ $\mathrm{mM}$ aqueous solution (B). The solution $\mathrm{A}$ was used without admixture, whereas the solution $B$ was made with a concentration of $25 \mathrm{ppm}$ with respect to Laspartic acid and $150 \mathrm{ppm}$ with respect to $\mathrm{NaHCO}_{3}$. Both solutions were kept at $\mathrm{pH} 7.4$ by admixture of Trizma. This $\mathrm{pH}$ was selected to make the HA appropriate for medical applications. Equal volumes of the solutions A and B (250 ml, each) were introduced simultaneously into a $1000 \mathrm{ml}$ beaker which was put into a $2450 \mathrm{MHz}$ microwave oven at maximum power for $5 \mathrm{~min}$. The microwave irradiated mixture was then quenched in ice for $30 \mathrm{~min}$. The precipitate was filtered, washed with water, and dried overnight at $55^{\circ} \mathrm{C}$. The powder thus obtained was characterized and found to be bouncy and free-flowing. The powder is composed of spherulites of about 2-4 $\mu \mathrm{m}$ in diameter, and the spherulite is composed of ultra-fine platelets of about $300 \mathrm{~nm}$. It is worth mentioning that the powder has a quite peculiar behavior on storage, in contrast with commercial apatites. Commercial powders usually tend to aggregate and form large solid lumps, whereas the powder produced by this method remains free-flowing after 3 years of storage in nonhermetically closed containers; thereby it may be considered as a suitable method for the synthesis of nanophase HA.

\section{ANALYSIS OF NANOPHASE HA}

This section highlights how the synthesized nanophase HA can be analyzed and the results are interpreted. Authors have recently reported the synthesis of nanophase HA by a wet chemical method and it has been systematically characterized to confirm their surface morphology, phase purity, crystal structure, crystallite or particle size, functional groups, and bioresorbability under physiological conditions ${ }^{[15]}$. In brief, $0.3 \mathrm{M}$ aqueous solution of $\left(\mathrm{NH}_{4}\right)_{2} \mathrm{HPO}_{4}$ was added drop wise to $0.5 \mathrm{M}$ aqueous solution of $\mathrm{CaCl}_{2}$ under a stirring condition of $1000 \mathrm{rpm}$ to form a reaction solution. The $\mathrm{pH}$ of the reaction solution was adjusted to 10 by adding concentrated $\mathrm{NH}_{4} \mathrm{OH}$ at $60^{\circ} \mathrm{C}$. A suspension of HA seed particles precipitated from the reaction solution was aged for $24 \mathrm{~h}$ and then subjected to microwave radiation for 15 minutes. The suspension was filtered, washed until there is complete removal of water soluble ammonium chloride $\left(\mathrm{NH}_{4} \mathrm{Cl}_{2}\right)$ and dried in a vacuum oven.
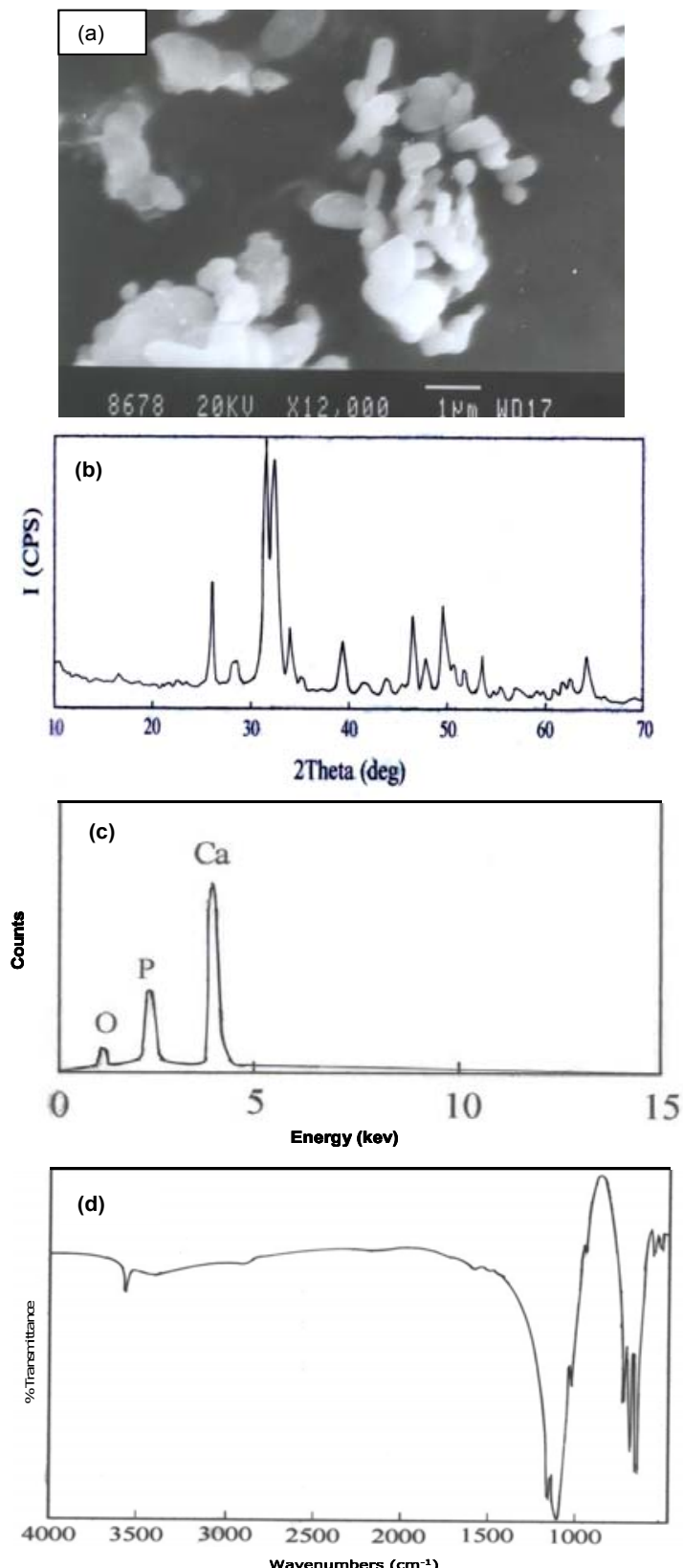

Fig. 1: Characteristic results of nanophase HA produced by a wet chemical method (a) SEM micrograph, showing its surface morphology, (b) X-ray diffraction pattern, showing its phase structure, (c) EDXA spectrum, showing its elemental composition, and (d) FTIR spectrum, showing its functional groups (Adapted with permission from ref. [15]).

The result shows that the size of the particles is in the nano-scale region with a mean particle size of $220 \mathrm{~nm}$ 
in diameter and most of them are not agglomerated, monodispersive, and having regular shape and cleaner contours. The crystallographic analysis was carried out by X-ray diffraction (XRD) method and a representative micrograph is shown in Fig. 1b. The result shows a typical apatite crystal structure with poor crystalline nature, due to the low temperature process, and does not show any extraneous phases, which suggests that the wet chemical reaction has produced phase pure HA.

Elemental distribution analysis was carried out by an energy dispersive X-ray analyzer (EDXA) and a representative micrograph is shown in Fig. 1c. The result shows that the nanophase HA is primarily composed of $\mathrm{Ca}$ and $\mathrm{P}$, which further confirms the purity of nano HA. Fourier transform infrared (FTIR) spectroscopy was employed to identify the functional groups and a representative micrograph is shown in Fig. $1 \mathrm{~d}$. The result shows all characteristic absorption peaks of HA. The peaks at 3567 and $634 \mathrm{~cm}^{-1}$ can be assigned to $\mathrm{OH}^{-}$stretching and bending vibration modes, respectively. A broad peak relating to $\mathrm{H}_{2} \mathrm{O}$ adsorption is noticed at about $3450 \mathrm{~cm}^{-1}$. The characteristic peak of $\mathrm{PO}_{4}{ }^{3-}$ group appeared at $1051 \mathrm{~cm}^{-}$ ${ }^{1}$, which has four distinct vibration modes namely $v_{1}$, $v_{2}, v_{3}$ and $v_{4}$ in the broad spectrum. The $v_{1}$ and $v_{2}$ vibration peaks are observed at $939 \mathrm{~cm}^{-1}$ and at 479 and $443 \mathrm{~cm}^{-1}$, respectively. As a major peak of phosphate group, the $v_{3}$ vibration peak is noticed in the region between 1120 and $955 \mathrm{~cm}^{-1}$. The band between 600 and $570 \mathrm{~cm}^{-1}$ indicated $v_{4}$ vibration mode of phosphate group, which occupies two sites in the crystal lattice each at 608 and $571 \mathrm{~cm}^{-1}$.

The in vitro bioresorbability test was performed in a stimulated body fluid (SBF) medium of $\mathrm{pH} 7.4$ at a ratio of $1 \mathrm{mg} / \mathrm{ml}$ in a thermostatic incubator at $37^{\circ} \mathrm{C}$. The changes in the $\mathrm{pH}$ of SBF medium were measured at pre-determined time intervals. The $\mathrm{pH}$ of the conventional HA was found to be of unvarying trend (not shown) as it was not resorbed in the medium whereas nano HA showed drastic changes in the $\mathrm{pH}$, suggesting that it dissolves much faster than conventional HA. The dissolution of calcium ions in the SBF medium was determined by an inductively coupled plasma atomic emission spectrometer (ICPAES). The release of calcium ions from the nano HA was quantitatively estimated to support its in vitro bioresorbability. It was found that more calcium ions are released from the nano HA compared to conventional HA, which may be due to catalytic related degradation of the nano HA and may also be due to their high surface area.

\section{CELLULAR RESPONSES OF NANOPHASE HA}

This section highlights cellular responses of nanophase HA at in vitro level. Huang et al. ${ }^{[22]}$ reported the in-vitro cell-compatibility of nano HA using human osteoblast-like cells (Fig. 2). The results

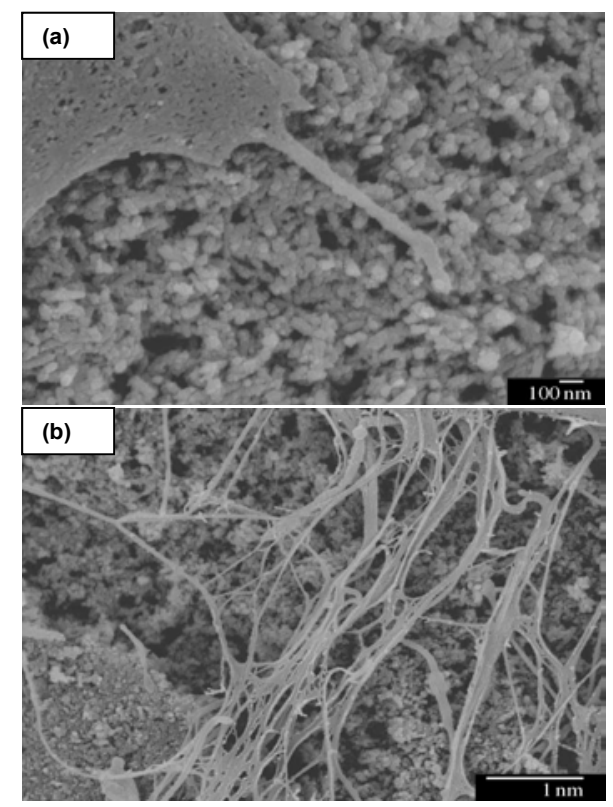

Fig. 2:SEM micrographs showing (a) the attachment of human osteoblast-like cells onto nano HA and (b) ECM produced by the cells onto nano HAsprayed glass substrate (Adapted with permission from ref. [22]).

confirmed the ability of nano HA in supporting cell adhesion and growth. The cells were able to attach to the nano HA surfaces and maintain their osteoblastic morphology with visible filapodia attached to nano HA particles (see Fig. 2(a)). There were large areas of confluent cells after seven days of culture and fiber-like ECM was produced (see Fig. 2(b)), which provides evidence for the better cell-matrix interactions. The invitro response of sol-gel derived nano HA with human MSCs was investigated in order to confirm its biocompatibility and bioactivity ${ }^{[23]}$. The in-vitro results showed that the human MSCs adhered to nano HA and exhibited better proliferation signals on their surface. Evidence of proliferation of MSCs was observed with a tendency to spread onto the surface as if forming groups, thus supporting not only biocompatibility but also enhanced bioactivity of the material. This 
behavior is considered important, since it simulates on an artificial surface several steps of the cell-cycle occurring in a tissue environment, with no need for an interfacial protein scaffold. The authors concluded that these surfaces interact with the MSCs in a manner that might be useful for tissue engineers to design scaffolds as an alternate to biological ECM.

The in-vitro studies on the enhanced functions of osteoblasts (bone-forming cells) on nanophase ceramic materials have been reported ${ }^{[24]}$. The authors extensively studied select functions of osteoblasts on nano HA (with grain size of $67 \mathrm{~nm}$ ) and conventional HA (with grain size of $179 \mathrm{~nm}$ ) using in-vitro cellular models. Osteoblasts were seeded onto the HA substrates and cultured under standard cell culture conditions. The results of cell culture studies (see Fig. 3) provided evidence of increased osteoblast proliferation onto nano HA when compared to conventional $\mathrm{HA}$ and to reference substrate (borosilicate glass). Although the osteoblast proliferation trend was similar on nanophase and conventional HA after 1 day of culture, it was significantly greater on nano HA after 3 and 5 days of culture, which indicates that the nanophase provides highly adhesive substrate to facilitate better cell adhesion and long-term cell growth. The results further

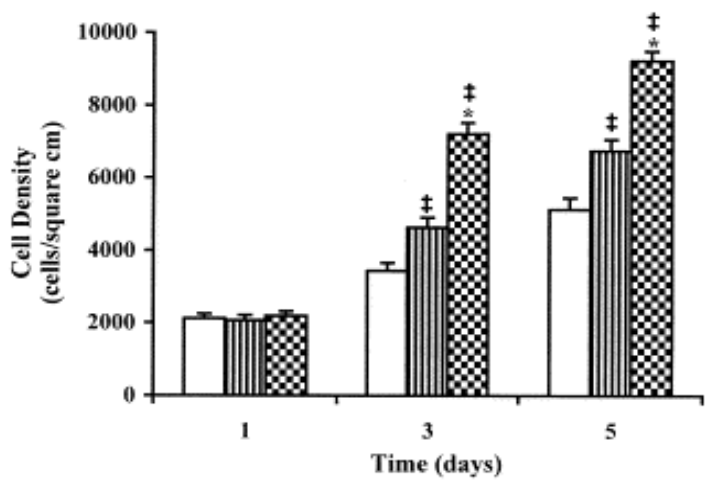

Fig. 3: Osteoblast proliferation on HA, under standard cell culture conditions $\left(37^{\circ} \mathrm{C}\right.$, humidified, $5 \%$ $\mathrm{CO}_{2} / 95 \%$ air environment), was determined after 1,3 , and 5 days. Values are mean $\pm \operatorname{SEM} ; n=3$; * $P<0.01$ (compared to respective conventional grain size ceramic); $\$ P<0.01$ (compared to borosilicate glass, a reference material). III denotes $179 \mathrm{~nm}$ grain size hydroxyapatite (conventional), and $\boldsymbol{\nabla}$ denotes $67 \mathrm{~nm}$ grain size hydroxyapatite (nanophase) (Adapted with permission from ref. [24]).

provided the evidence of enhanced long-term functions, in particular synthesis of alkaline phosphatase and concentration of calcium in the ECM, of osteoblasts cultured on nano HA than on conventional HA. These experimental results revealed that the nanophase HA positively enhanced the cell adhesion, migration, differentiation, cell-matrix interactions and subsequent bone tissue formation and thus it may be a potentially ideal scaffolding system for bone tissue engineering.

\section{CONCLUSION}

Bone tissue engineering is emerging as a potential solution to traditional bone tissue transplantations. Use of nanophase HA in engineering bone tissues is at the infant stage and still growing. Although preliminary investigations seem to support the impact of nanophase HA in bone tissue engineering, significant advancements are necessary to realize their full potential in clinical use. It is also noted that bone implants/grafts made of nano HA are relatively less available than their microscale counterparts ${ }^{[25]}$, but there is a trend toward using nanophase HA due to its superior surface properties favorable for cell growth, cell-matrix interaction, tissue formation and continued function. This is an exciting time to be involved in nanophase HA in order to formulate them as a clinically ideal system for bone tissue engineering, with great challenges and also great expectations ahead.

\section{REFERENCES}

1. Murugan R and S. Ramakrishna, 2005. Development of nanocomposites for bone grafting. Comp. Sci. Tech., 65: 2385-2406.

2. Chang, Y.L., C.M. Stanford and J.C. Keller, 2000. Calcium and phosphate supplementation promotes bone cell mineralization: Implications for hydroxyapatite (HA)-enhanced bone formation. J. Biomed. Mater. Res., 52; 270-278.

3. Goto, T., T. Kojima, T. Iijima, S. Yokokura, H. Kawano, A. Yamamotto and K. Matsuda, 2001. Resorption of synthetic porous hydroxyapatite and replacement by newly formed bone. J. Orthop. Sci., 6; 444-447.

4. Murugan, R and S. Ramakrishna, 2004. Nanostructured biomaterials. Encyclopedia of Nanoscience and Nanotechnology, American Scientific Publishers, CA, USA., 7; 595-613.

5. Aoki, H., 1994. Medical Applications of Hydroxyapatite. Ishiyaku EuroAmerica Inc., Tokyo.

6. Shinto. Y., A. Uchida, F. Korkusuz, F. Araki and K. Ono, 1992. Calcium hydroxyapatite ceramic used as a delivery system for antibiotics. J. Bone Joint Surg. Br., 74-B; 600-604. 
7. Murugan, R and K.P. Rao, 2002. Controlled release of antibiotic from surface modified coralline hydroxyapatite. Trends Biomater. Artif. Organs, 16; 43-45.

8. Murugan, R., K.P. Rao and T.S.S. Kumar, 2002. Microwave synthesis of bioresorbable carbonated hydroxyapatite using goniopora. Bioceramics, 15: 51-54.

9. Murugan, R and S. Ramakrishna, 2004. Coupling of therapeutic molecules onto surface modified coralline hydroxyapatite. Biomaterials, 25: 3073-3080.

10. Murugan, R and S. Ramakrishna, 2005. Porous bovine hydroxyapatite for drug delivery., J. Appl. Biomater. Biomech., 3: 93-97.

11. Murugan, R., T.S.S. Kumar and K.P. Rao, 2002. Fluorinated bovine hydroxyapatite: Preparation and characterization. Mater. Lett., 57: 429-433.

12. Murugan, R and S. Ramakrishna, 2005. Crystallographic study of hydroxyapatite bioceramics derived from various sources. Crystal Growth Design 5: 111-112.

13. Webster, T.J., C. Ergan, R.H. Doremus, R.W. Siegel and R. Bizios, 2000. Enhanced functions of osteoblasts on nanophase ceramics. Biomaterials, 21: 1803-1810.

14. Huang, J., S.M. Best, W. Bonfield, R.A. Brooks, N. Rushton, S.N. Jayasinghe and M.J. Edirisinghe, 2004. In vitro assessment of the biological response to nano-sized hydroxyapatite. J. Mater. Sci. Mater. Med., 15: 441-445.

15. Murugan, R and S. Ramakrishna, 2005. Aqueous mediated synthesis of bioresorbable nanocrystalline hydroxyapatite. J. Cryst. Growth, 274: 209-213.

16. Ota, Y and Iwashita, 1998. Novel preparation method of hydroxyapatite fibers. J. Am. Ceram. Soc., 81: 1665-1668.

17. Zhang, S and K.E. Consalves, 1997. Preparation and characterization of thermally stable nanohydroxyapatite. J. Mater. Sci. Mater. Med., 8: $25-28$.
18. Kothapalli, C.R., M.T. Shaw and M. Wei, 2005. Biodegradable HA-PLA 3-D porous scaffolds: Effect of nano-sized filler content on scaffold properties. Acta Biomaterialia, 1: 653-662.

19. Nakamura, S., T. Tsobe and M. Senna, 2001. Hydroxyapatite nano sol prepared via a mechanochemical route. J. Nanopart. Res., 3: 5761.

20. Koumoulidis, G.C., T.C. Vaimakis, A.T. Sdoukos, N.K. Boukos and C.C Trapalis, 2001. Preparation of hydroxyapatite lathlike particles using high-speed dispersing equipment. J. Am. Ceram. Soc., 84: 1203-1208.

21. Sarig, S and F. Kahana, 2002. Rapid formation of nanocrystalline apatite., J. Crystal Growth, 237-239: 55-59.

22. Huang, J., S.M. Best, W. Bonfield, R.A. Brooks, N. Rushton, S.N. Jayasinghe and M.J. Edirisinghe, 2004. In vitro assessment of the biological response to nano-sized hydroxyapatite. J. Mater. Sci. Mater. Med., 15: 441-445.

23. Manso, M., S. Ogueta, P.H. Fernandez, L. Vazquezl, M. Langlet, J.P.G. Ruiz, 2002. Biological evaluation of aerosol-gel-derived hydroxyapatite coatings with human mesenchymal stem cells. Biomaterials, 23: 39853990.

24. Webster, T.J., C. Ergan, R.H. Doremus, R.W. Siegel and R. Bizios, 2000. Enhanced functions of osteoblasts on nanophase ceramics., Biomaterials, 21: 1803-1810.

25. Murugan R and S. Ramakrishna, 2005. Bioactive nanomaterials in bone grafting and tissue engineering. In: Handbook of Nanostructured Biomaterials and their Applications in Nanobiotechnology, H. S. Nalwa (Ed.), American Scientific Publishers, CA, USA, 2: 141-168. 